\title{
A Comprehensive Profile of Decoding and Comprehension in Autism Spectrum Disorders
}

\author{
Sabine V. Huemer • Virginia Mann
}

Published online: 14 November 2009

(c) The Author(s) 2009. This article is published with open access at Springerlink.com

\begin{abstract}
The present study examined intake data from 384 participants with autism spectrum disorders (ASD) and a comparison group of 100 participants with dyslexia on nine standardized measures of decoding and comprehension. Although diagnostic groups were based on parental reports and could not be verified independently, we were able to observe significant distinctions between subject groups. Overall findings confirm previous results of a disassociation between decoding and comprehension in ASD. Using a larger sample than previous studies and a greater variety of measures, a pattern of relatively intact decoding skills paired with low comprehension was found in autism, PDD-NOS, and Asperger's. In contrast, the dyslexic group showed the opposite pattern of stronger comprehension and weaker decoding.
\end{abstract}

Keywords Autism spectrum disorders - Decoding · Comprehension $\cdot$ Reading $\cdot$ Dyslexia

A successful reader has the ability to accurately and fluently decode words so as to comprehend their meaning in isolation and in context. For many children, decoding skills and reading comprehension develop hand in hand (Mirenda

This study was originally prepared as the Sabine V.Huemer's master thesis at Antioch University Los Angeles.

S. V. Huemer · V. Mann

Department of Cognitive Sciences, University of California, Irvine, 2201 Social \& Behavioral Sciences Gateway Building (SBS), Irvine, CA 92697-5100, USA

S. V. Huemer $(\bowtie)$

1215 S. Gertruda Ave., Redondo Beach, CA 90277, USA

e-mail: shuemer@uci.edu
2003; Nation and Norbury 2005). Children with ASD, however, have been reported to show a disassociation between decoding and comprehension: while decoding skills in high-functioning children with autism and Asperger's syndrome may be intact (Frith and Snowling 1983; Griswold et al. 2002; O'Connor and Klein 2004), their reading comprehension is often lower than expected for their level of reading ability (Minshew et al. 1994; O'Connor and Hermelin 1994). Several studies have examined the connection between poor reading comprehension and autism (Nation et al. 2006; Nation and Norbury 2005; Wahlberg and Magliano 2004). Comprehension problems in ASD may be due to difficulties integrating information in context (Frith 2003), deficits in verbal skills and oral language ability (Mirenda and Erickson 2000, pp. 349-351), impairments in communication (Nation and Norbury 2005), and/or general language impairment (Tager-Flusberg and Joseph 2003).

Early on, Kanner (1943), and also Ricks and Wing (1975) wrote about reading comprehension problems in the context of other language deficits in autism, such as literal speech dominated by the use of concrete words. Later studies of single-word comprehension suggested that ASD individuals can mentally represent at least some singleword meanings: Colors (Bryson 1983) as well as concrete and abstract words (Eskes et al. 1990) all appear to be processed normally. It is the comprehension of linguistic units beyond the word level that present increased difficulty for ASD individuals (O'Connor and Klein 2004). Wahlberg and Magliano (2004) reported that high-functioning readers with autism had difficulty understanding written text, likely because they were not able to draw in relevant background information to interpret ambiguities in discourse. Other comprehension tasks related to understanding a sequence of words, such as following complex 
oral instructions, have been shown to be impaired even in high-functioning individuals with autism (Goldstein et al. 1994). These findings underscore the disassociation of form (language structure) and function (language use) present in autism (Tager-Flusberg 1981; Tager-Flusberg and Joseph 2003).

While reading comprehension is impaired, the comprehension deficits in ASD are not likely to be the result of poor decoding skills. Previous research found that ASD students were as skilled in nonword reading as typically developing controls (Frith and Snowling 1983) and showed the expected advantage for reading phonetically regular words more easily than phonetically irregular words demonstrating a phonetic decoding strategy alongside intact lexical skills for familiar words (O'Connor and Klein 2004). Minshew et al. (1994) found general patterns of stronger word-reading skills in the presence of deficits in language comprehension and abstract reasoning in children with high-functioning autism and Asperger's. Thus, at least one aspect of structure, the phonetic structure of words, appears relatively intact among some of the diagnostic categories in ASD.

Higher level elements of decoding, however, have been shown to be impaired or delayed in autism (Tager-Flusberg et al. 1990), especially when it comes to more complex grammatical structures. These higher-level skills impact comprehension but they are also influenced by comprehension, which facilitates contextual decoding. Therefore, fluent reading of meaningful text can pose a challenge to the ASD population, since this task requires complex multi-dimensional cognitive abilities and relies more heavily on general linguistic and semantic skills than on word-level measures of decoding (Nation and Snowling 1997). Fluent reading involves decoding with concurrent processes activated, such as the processing of syntax and semantics (Katzir et al. 2006), which would predict that ASD children will be less efficient text-readers than singleword readers.

In one of the few systematic studies of reading skills in autism, Nation et al. (2006) assessed 41 children with ASD in four components of reading skills: word recognition, nonword decoding, text-reading accuracy, and reading comprehension. Nation reported that $65 \%$ of the participants showed poor reading comprehension with standard scores at least one SD below population norms. Of the 32 children with measurable reading ability (nine of the youngest children, or $22 \%$, were completely unable to read), $10.3 \%$ achieved reading comprehension scores at least two SDs below their reading accuracy scores. All but one of the participants showed reading comprehension skills below decoding skills, clearly demonstrating a discrepancy between the two elements. Contrary to Frith and Snowling (1983), Nation's group of participants also showed problems in decoding nonwords: $42 \%$ were at least one SD below population norms and $22 \%$ at least two SDs below population norms which may be linked to poor phonological processing. Nation concludes that many children with ASD have low levels of reading accuracy and she implicates low decoding skills as one of the factors in reading comprehension deficits in ASD.

In contrast to the ASD population, children with dyslexia tend to be poor decoders despite adequate linguistic comprehension and intellectual functioning. Where visual reversals were once thought to be responsible, the present consensus offered by the International Dyslexia Association (2002) and the National Institute of Health (2002) is that dyslexia is a specific learning disability that is neurological in origin and characterized by difficulties with accurate and/or fluent word recognition and by poor spelling and decoding abilities. These difficulties typically result from a deficit in the phonological component of language that is often unexpected in relation to other cognitive abilities and the provision of effective classroom instruction. Secondary consequences may include problems in reading comprehension and reduced reading experience that can impede the growth of vocabulary and background knowledge (International Dyslexia Association 2002; National Institute of Health 2002). But in dyslexia the problem starts with inadequate decoding whereas in ASD the problem appears to lie in recovering the linguistic and semantic structure and in relating the meaning of a text to background information.

According to the two above mentioned sources and confirmed by a wealth of research, phonological deficits are the underlying reason for the decoding errors in dyslexic individuals (Beaton 2004; Bishop and Snowling 2004; Catts and Kamhi 2005; Mann 2002). Dyslexics show some comprehension problems with both spoken and written sentences (e.g., Mann et al. 1984; Shankweiler et al. 1984; Smith et al. 1986; see Mann 2002, for a review) but these are regarded as the consequences of poor working memory for phonological information and not as a problem with syntactic or semantic structure.

Phonological decoding is typically measured by an individual's performance on nonword reading tasks, which is widely considered one of the most critical predictors of successful reading acquisition (Snowling 2000; Ziegler and Goswami 2006). In nonword reading tasks, readers are required to connect novel letter strings to sequences of phonemes that are not words but could exist in their phonological lexicon. Dyslexics show difficulty in reading unfamiliar words and nonwords compared to known words (Harm and Seidenberg 2000). They tend to be less fluent readers, achieving fewer words per minute in timed oral reading tests (Bowers 1993; Catts and Kamhi 2005). Thus, where dyslexics are inordinately poor 
decoders, people with ASD tend to be inordinately poor comprehenders.

The present study takes advantage of a large-scale intervention program that seeks to ameliorate reading and reading comprehension problems among poor readers including those with a diagnosis of ASD and dyslexia. The large sample available to this study, the variety of standardized tests of decoding, the inclusion of written and oral comprehension measures, and the reporting of subgroup data (autism, PDD-NOS, Asperger's) were clear advantages that made the current study informative even though all grouping was based on parental report and not clinical assessment records. Lastly, the present study holds the ASD findings up against findings from a comparison group with dyslexia which was expected to show the reverse pattern of the decoding-comprehension disassociation. Intake data was the concern of the analysis, the outcome of treatment was not. Extrapolating from the literature, we hypothesized that, at intake:

1. Both oral and written comprehension tasks will show greater impairment in the ASD groups than in the dyslexia group supporting evidence of inordinately poor comprehension in ASD.

2. Decoding tasks will show greater impairment in the dyslexia group than in all ASD groups. The latter are expected to have scores for nonword and sight word decoding above their text reading scores.

3. The Asperger's group should consistently outscore the two other ASD groups in all measures, with the autism group trailing the PDD-NOS group by a small margin based on a slightly higher level of general cognitive functioning in PDD-NOS, as described in the Diagnostic and Statistic Manual of Mental Disorders, TextRevision, DSM-IV-TR (American Psychiatric Association 2000).

\section{Method}

\section{Participants}

The current study utilized 2001-2006 clinical intake data from Lindamood-Bell Learning Processes (LBLP), a network of private, nationwide learning centers specializing in one-on-one reading and reading comprehension instruction for individuals with learning disabilities and developmental disorders, such as dyslexia and ASD. Two of the programs administered at LBLP specifically address issues of decoding and comprehension, another one stimulates phoneme awareness to optimize decoding. The 42 LBLP centers and additional summer sites are located in predominantly affluent parts of major U.S. cities; one learning
Table 1 Participants by primary diagnosis and ethnicity

\begin{tabular}{lrrrrr}
\hline Ethnicity & Autism & Asperger's & $\begin{array}{c}\text { PDD- } \\
\text { NOS }\end{array}$ & Dyslexia & Total \\
\hline African-American & 2 & 4 & 1 & 5 & 12 \\
Asian & 27 & 10 & 14 & 3 & 54 \\
Caucasian & 103 & 73 & 76 & 68 & 320 \\
Hispanic & 16 & 1 & 7 & 9 & 33 \\
Other & 6 & 3 & 9 & 4 & 22 \\
Not reported & 17 & 3 & 12 & 11 & 43 \\
Total $N$ & 171 & 94 & 119 & 100 & 484 \\
\hline
\end{tabular}

center is located in London, England. Data for the present study were collected at all 42 LBLP center locations and five summer sites.

The study data included intake test results from nine measures of decoding and comprehension from 171 individuals with autism (26 females and 145 males with an average age of 10.41 years), 94 individuals with Asperger's (14 females and 80 males with an average age of 11.37 years), and 119 individuals with PDD-NOS (28 females and 91 males with an average age of 10.08 years). The comparison group of dyslexic individuals included 100 children and adolescents ( 45 females and 55 males with an average age of 11.21 years). See Table 1 for more demographic information by diagnostic group.

The primary diagnosis, which was reported upon intake by the student's parent or caretaker, was the main selection criteria for the data analyzed in the present study. Despite the limitation of a diagnosis based on parental report, we did not want to dismiss the valuable subset data made available by LBLP distinguishing between autism, PDDNOS, and Asperger's. To our knowledge, no systematic ASD reading and/or comprehension study with this kind of subset data exists. Information on secondary diagnoses or co-morbidities was not part of the data set and is often less reported and underdiagnosed.

While nearly half of the general ASD population has little or no speech, functions within the mentally retarded range, and, consequently, does not have measurable reading skills (Nation and Norbury 2005) all subjects in the present study were verbal and had measurable reading abilities. Another bias of the research data set lies in the fact that LBLP clients are typically school-aged children with at least some hope of academic progress. Therefore, the ASD sample of this study represents a very specific slice of the general ASD population.

Lindamood-Bell's 2006 clinical statistics show that $45 \%$ of LBLP students received prior speech therapy, 37\% received prior special education services, and 33\% reported prior remedial reading instruction. The data also show that $18 \%$ of clients had previously repeated a grade and $11 \%$ 
were diagnosed as gifted. Most LBLP students reported a prior diagnosis. Twenty-eight percent of the students who received instruction at LBLP in 2006 had a primary diagnosis of dyslexia, $13 \%$ were diagnosed with ADD, $16 \%$ with ADHD, $13 \%$ with ASD, 5\% with Central Auditory Processing Disorder, and 25\% with another or no diagnosis. The average referral age for children with ASD was 10.7 years with $18 \%$ females and $82 \%$ males. The average age for referrals diagnosed with dyslexia was 11.0 years with $42 \%$ females and $58 \%$ males (LBLP 2007).

\section{Materials}

The ASD data for this study were collected between 2001 and 2006 and represent all ASD data collected by LBLP during that time period. The investigators excluded data sets of three participants with autism ( 1 female and 2 male) due to a lack of test results. The dyslexia data were a simple random sample of 100 participants out of a complete set of 372 dyslexia data collected between 2005 and 2006. The sample was drawn by a representative of the LBLP Research \& Development Department using SAS (Statistical Analysis Software). Participants' names and birth dates were omitted to protect the students' identity. Only de-identified data were seen and used by the investigators. Data for each participant included information on age (years and months), grade, gender, ethnicity, pretest date and site, diagnosis, and pre-treatment test data (raw scores and standard scores) of the measures discussed in this section from the years indicated above.

Before a prospective student begins instruction at LBLP, an experienced clinician trained in test taking administers a standard psychometric test battery to determine specific weaknesses and strengths of decoding and comprehension. The core test battery includes the tests analyzed in the present study. The variety of measures therefore carries an inevitable bias of having been selected by LBLP. While results from nine measures were analyzed in this study, some of the measures are not the most current versions used in clinical practice today.

The children tested typically undergo the full test battery in one block of about $4 \mathrm{~h}$ with breaks between tests, or, in the case of younger children, in two blocks of $2 \mathrm{~h}$ administered on two consecutive days. Data sets for each participant showed that, with the exception of the three excluded subjects, most children took most of the tests. After testing, raw test scores are calculated and verified by at least one more LBLP employee trained in testing. Scores are then analyzed by a software program developed by LBLP and accessible in all LBLP locations. Should a scoring error be detected, at least one more LBLP employee is assigned to provide another layer of test score verification.
What follows is a list of all measures included in this study beginning with four decoding measures followed by five comprehension measures ${ }^{1}$ :

Woodcock reading mastery test-revised (WRMT-R) word attack. Individuals are asked to read isolated nonwords or pseudo words (Woodcock 1987).

Slosson oral reading test-revised (SORT-R). Individuals decode from lists of isolated real words, assessing word recognition abilities (Slosson 1990).

Gray oral reading test-revised, 4th edition (GORT-4). The subtests for rate and accuracy were analyzed in the present study (Wiederholt 1991).

Lindamood auditory conceptualization test (LAC-3). This test measures an individual's ability to perceive and conceptualize speech sounds using a visual medium. Subtests include sound tracking with blocks and syllable-tracking with felts from given auditory stimuli (Lindamood and Lindamood 2004).

Peabody picture vocabulary test third edition (PPVTIII). This test is a wide-range measure for receptive oral vocabulary of Standard English and a screening test for verbal ability. Individuals are asked to look at a choice of four simple black-ink drawings per page and select the picture that best matches an auditory stimulus (Dunn and Dunn 1997).

Detroit tests of learning aptitude-4th edition (DTLA-4) word opposites. Individuals have to verbally express one word that is exactly the opposite of an auditorily presented stimulus word. For example, "What is the opposite of 'day'?" This measure assesses verbal expression skills and general intelligence (Hammill 1991).

Detroit tests of learning aptitude-2nd edition (DTLA-2) oral directions. This test assesses the ability to mark visual material after oral directions have been given. For example, the examiner gives an oral direction such as: "Draw a line from one circle to the other circle that does not touch the square" (Banas 1989). This test is no longer available for clinical practice but LBLP has special permission from the publisher to use this tool.

GORT-4 comprehension. Individuals read passages aloud and answer five multiple choice comprehension questions after completing each passage (Wiederholt 1991).

\footnotetext{
1 Three additional tests were available for a subset of participants: the WRAT-3 for sight word reading which, at times, substitutes for the SORT-R, the TOPS-R, and the TOPS-A, both measures of critical thinking normed for children and adolescents/adults. The data from these measures were insufficient in order to permit inclusion in the analyses.
} 


\section{Procedure}

All data were provided as Excel files by the LindamoodBell Research \& Development Department in San Luis Obispo, California, and included diagnosis, age, grade, gender, ethnicity, center location, and test results. The investigators analyzed the data in SPSS. Normed standard scores were used whenever possible to analyze all data. $Z$-transforms of the data were used to standardize the range of scores, and factor analysis was used for data-reduction procedures. Missing scores were replaced by the population mean.

\section{Results}

To test our predictions regarding the relative asymmetry between decoding and comprehension, data from all participants were subjected to a factor analysis of $Z$-scores. This revealed two factors that accounted for $70 \%$ of all score variances. Varimax rotation with Kaiser Normalization revealed the loads that appear in Table 2 .

In general, the tests clustered as we had expected: Factor 1 , accounting for $36 \%$ of variance, includes four of the decoding measures at 0.8 or higher. Of the decoding measures, only the LAC-3 test failed to load heavily on this factor. That test loaded relatively higher on factor 2 , which accounts for $34 \%$ of the variance; its primary load was the four comprehension measures that loaded at 0.7 or higher.

The two factor scores were then computed for individual subjects and treated to a repeated-measures GLM with diagnostic group as a between-subject factor. Table 3 shows each mean factor score for the four diagnostic groups and their average.

Table 2 Factor analysis of standard scores (Z-transforms)

\begin{tabular}{lll}
\hline Test & Factor 1 & Factor 2 \\
\hline Comprehension & & \\
PPVT-III & .09 & .87 \\
DTLA-4 word opposites & .30 & .76 \\
DTLA-2 oral directions & .05 & .86 \\
GORT-4 comprehension & .25 & .74 \\
Decoding & & \\
WRMT-R word attack & .84 & .14 \\
SORT-R & .90 & .21 \\
GORT-4 rate & .83 & .20 \\
GORT-4 accuracy & .87 & .22 \\
LAC-3 & .33 & .50 \\
\hline
\end{tabular}

Factor 1 and factor 2 account for $70 \%$ of total scores. Z-scores were derived from standard scores across all diagnostic groups. Rotation: Varimax with Kaiser Normalization
Table 3 Factor scores: means and SD as a function of diagnosis

\begin{tabular}{|c|c|c|c|c|c|c|c|}
\hline \multirow[t]{2}{*}{ Diagnosis } & \multirow[t]{2}{*}{$N$} & \multicolumn{2}{|c|}{ Decoding } & \multicolumn{2}{|c|}{ Comprehension } & \multicolumn{2}{|c|}{ Average } \\
\hline & & $M$ & SD & $M$ & SD & $M$ & SD \\
\hline Autism & 171 & .13 & .07 & -.54 & .06 & -.21 & .05 \\
\hline PDD-NOS & 119 & -.01 & .09 & -.28 & .08 & -.14 & .06 \\
\hline Asperger's & 94 & .28 & .10 & .35 & .09 & .31 & .07 \\
\hline Dyslexia & 100 & -.47 & .10 & .93 & .08 & .23 & .07 \\
\hline All subjects & 484 & -.02 & .05 & .12 & .04 & & \\
\hline
\end{tabular}

There is a small main effect of factor score, $F(1$, $480)=5.70, \mathrm{MSE}=4.06, p<.02$, reflecting a trend for factor scores on decoding to be lower than those on comprehension. There is also a more substantial main effect of diagnostic group, $F(3,480)=18.09, \quad \mathrm{MSE}=16.36$, $p<.01$, reflecting a trend for participants with autism to have the lowest factor scores, on average, followed by the PDD-NOS group, the dyslexia group, and the Asperger's group, in that order.

More central to our concern was the very significant interaction between factor and diagnostic group, $F(3$, $480)=66.08$, MSE $=47.06, p<.01$. Post-hoc Tukey HSD comparisons of the effect of diagnostic group indicated that group differences between the dyslexia group and the autism group were significant at $p<.01$ but that those between autism and PDD-NOS and Asperger's and dyslexia were not, $p>.85$. However, consideration of individual factor scores revealed that, on the decoding factor (factor 1), the three ASD groups scored at or above the population mean whereas the dyslexia group scored below the mean. On the comprehension factor (factor 2), the autism and the PDD-NOS groups scored below the population mean, and the Asperger's and the dyslexia groups scored above. The disassociation between decoding and comprehension skills was therefore most evident between the two "extreme" diagnostic groups, autism and dyslexia. The PDD-NOS group resembles the autism group and the Asperger's group falls in between, with decoding scores like the autism group but comprehension scores closer to the dyslexia group.

In an additional GLM with repeated measures of the two factor scores we controlled for age, gender, and center location as co-variants and found that neither gender nor center location had any effects between subjects, $p>.05$. While age showed an effect on factor scores, $F(3,477)=9.94, p<.01$, there was no interaction with the diagnosis. A MANCOVA of standard scores was used to examine the effects of age across all measures. The analysis confirmed that older children tended to do worse than younger ones: age had effects in the PPVT-III, DTLA-2 Oral Directions, and the GORT-4 Comprehension as well as in the WRMT-R Word Attack, the SORT-R, and the GORT-4 Rate, $p<.01$. 
Table 4 gives a summary of mean standard scores achieved by each diagnostic group on each measure.

As predicted, all decoding measures showed lower scores among the dyslexia group as compared to the ASD groups, with the exception of the LAC-3 test, and comprehension measures show the opposite trend of higher comprehension scores for participants with dyslexia than participants with ASD.

\section{Discussion}

The present study examined decoding and comprehension in individuals with ASD with the goal of confirming previous studies using a bigger sample with a greater variety of measures and presenting rare subset data for autism, PDD-NOS, and Asperger's. The ASD groups' performance on nine standardized psychometric tests was further compared to the performance of a dyslexia comparison group. Given the number of tests available for analysis, factor analysis was used to reduce the data.

As predicted, participants with ASD achieved lower scores on all comprehension measures compared to participants with ASD whereas the dyslexia comparison group showed lower scores on all decoding measures than the ASD groups. The expected asymmetrical disassociation between decoding and comprehension became especially apparent when the autism and the PDD-NOS were compared to dyslexia. The exception to the asymmetry between the ASD groups and the dyslexia group occurred on the LAC-3, a test of phoneme awareness that behaved partly like a comprehension test and partly like a decoding test.

The results from the ASD groups support findings of comprehension skills that lie below decoding skills in highfunctioning autism (Minshew et al. 1994; Mirenda and Erickson 2000; Nation et al. 2006; O'Connor and Klein 2004; O'Connor and Hermelin 1994). The results from the dyslexia group are also consistent with a definition of dyslexia as decoding that is unexpectedly below the child's other cognitive abilities (International Dyslexia Association 2002; National Institute of Health 2002). They further show that the reading skills associated with PDD-NOS closely resemble autism whereas Asperger's associates with a relatively high level of reading skills across both decoding and comprehension.

Gender and clinic location had no effect on our results regarding the disassociation between decoding and comprehension and its relation to diagnostic category. Age covaried with some measures. Interestingly, the Asperger's group was the only group that showed an improvement with increased age while the other groups fell further behind the population norm. Previous studies reported that children with Asperger's have higher verbal and oral
Table 4 Means and SDs of all measures of decoding and comprehension

\begin{tabular}{|c|c|c|c|}
\hline Test/diagnosis & $N$ & $M$ & SD \\
\hline \multicolumn{4}{|c|}{ WRMT-R word attack ${ }^{\mathrm{a}}$} \\
\hline Autism & 164 & 95.98 & 16.82 \\
\hline PDD-NOS & 110 & 93.42 & 16.23 \\
\hline Asperger's & 92 & 99.70 & 15.49 \\
\hline Dyslexia & 99 & 91.75 & 11.38 \\
\hline \multicolumn{4}{|l|}{ SORT-R $^{\mathrm{a}}$} \\
\hline Autism & 167 & 90.31 & 21.55 \\
\hline PDD-NOS & 112 & 88.72 & 21.14 \\
\hline Asperger's & 92 & 95.37 & 18.75 \\
\hline Dyslexia & 98 & 84.97 & 16.60 \\
\hline \multicolumn{4}{|l|}{ GORT-4 rate } \\
\hline Autism & 145 & 6.85 & 3.46 \\
\hline PDD-NOS & 83 & 6.60 & 3.26 \\
\hline Asperger's & 78 & 8.09 & 3.85 \\
\hline Dyslexia & 96 & 6.11 & 2.76 \\
\hline \multicolumn{4}{|c|}{ GORT-4 accuracy ${ }^{\mathrm{b}}$} \\
\hline Autism & 145 & 6.67 & 3.50 \\
\hline PDD-NOS & 83 & 6.64 & 3.41 \\
\hline Asperger's & 78 & 8.36 & 4.11 \\
\hline Dyslexia & 98 & 6.45 & 3.02 \\
\hline \multicolumn{4}{|l|}{ LAC $-3^{\mathrm{a}}$} \\
\hline Autism & 69 & 80.94 & 18.63 \\
\hline PDD-NOS & 43 & 83.09 & 17.56 \\
\hline Asperger's & 44 & 91.64 & 18.79 \\
\hline Dyslexia & 97 & 90.26 & 11.13 \\
\hline \multicolumn{4}{|l|}{ PPVT-III $^{\mathrm{a}}$} \\
\hline Autism & 170 & 76.83 & 17.87 \\
\hline PDD-NOS & 118 & 82.62 & 15.15 \\
\hline Asperger's & 92 & 95.15 & 19.38 \\
\hline Dyslexia & 100 & 101.67 & 13.68 \\
\hline \multicolumn{4}{|c|}{ DTLA-4 word opposites ${ }^{\text {b }}$} \\
\hline Autism & 159 & 5.28 & 3.39 \\
\hline PDD-NOS & 111 & 6.09 & 3.78 \\
\hline Asperger's & 89 & 8.30 & 3.77 \\
\hline Dyslexia & 94 & 8.28 & 3.07 \\
\hline \multicolumn{4}{|c|}{ DTLA-2 oral directions ${ }^{\mathrm{b}}$} \\
\hline Autism & 156 & 3.85 & 3.01 \\
\hline PDD-NOS & 110 & 4.00 & 2.81 \\
\hline Asperger's & 90 & 6.32 & 3.29 \\
\hline Dyslexia & 99 & 8.19 & 2.89 \\
\hline \multicolumn{4}{|c|}{ GORT-4 comprehension ${ }^{\mathrm{b}}$} \\
\hline Autism & 145 & 4.48 & 3.05 \\
\hline PDD-NOS & 84 & 5.21 & 3.01 \\
\hline Asperger's & 78 & 7.10 & 3.63 \\
\hline Dyslexia & 96 & 8.37 & 3.12 \\
\hline
\end{tabular}

95\% confidence interval

${ }^{\text {a }}$ Mean $=100, \mathrm{SD}=15$

${ }^{\mathrm{b}}$ Mean $=10, \mathrm{SD}=3$ 
language skills than children with high-functioning autism (Iwanga et al. 2000; Klin et al. 1995; Ozonoff et al. 1991, 2000) which is commensurate with the strong overall performance by the Asperger's group in our study.

The relatively high achievement of all ASD groups in isolated word reading (WRMT-R Word Attack and SORT$\mathrm{R})$ is possibly the single most remarkable finding of this study. In the general population, nonword reading is the best predictor for reading success (Snowling 2000; Ziegler and Goswami 2006) among children seeking intervention for reading problems. Apparently, the comprehension problems in children with ASD stem from difficulties above and beyond the ability to recover the phonological structures transcribed by the English alphabet. In this regard, our finding of relatively intact decoding in Asperger's and autism differs from Nation et al. (2006) who showed that $46 \%$ of their 41 ASD participants were at least one SD below norm and $22 \%$ were at least two SD below norm in decoding. The present study included a much larger sample but did not include non-readers like those who had participated in Nation's study.

Against predictions, results from the phonological awareness measure (LAC-3) loaded on both the decoding and comprehension factors, and not particularly well on either. The LAC-3 placed the dyslexia group second after the Asperger's group and showed the autism group to be clearly at the bottom. Since the LAC-3 was the sole phonological measure in this study, a variety of explanations might filter into the interpretation of the results. The dyslexia group could have received and benefited from prior intervention in phonological awareness at school, a likely scenario considering their diagnosis and the fact that LBLP is often pursued after years of public education have failed. But we suspect a more likely reason is that the participants with autism and PDD-NOS found the LAC-3 difficult because it places demands on the ability to follow arbitrary oral instructions. Oral commands within the LAC-3, such as asking participants to track nonword sounds and syllables with color-coded blocks and felts, may challenge these groups with their known problems with oral instructions (Goldstein et al. 1994) and receptive language comprehension (Mirenda and Erickson 2000). Nation (1999) considers the LAC an excellent predictor of first-grade reading skills, and that does appear to be the case for the general population. However, three hyperlexic children performed well below age-expected levels on the LAC in a study conducted by Sparks (1995). For the present study, which involves ASD children with known oral instruction deficits, we are inclined to consider the LAC-3 as a confounded test that measured both oral comprehension and phonological awareness.

The primary limitation of this study was the very nature of archival research which confines the parameters of the study to a given set of data. The positive aspect of this type of research is that large sample sizes tend to show clearer patterns in subpopulations. However, limited by the existing LBLP dataset, we had to work with a self-reported diagnosis by parents which did not include secondary diagnoses or co-morbidities. Therefore, the subset data has to be regarded as a secondary analysis that possibly hints at trends but cannot be conclusive. Self-reports of diagnosis have been used in previous ASD research. Reichenberg et al. (2006) used reports from Israeli draft-board assessments in a population-based cohort study to determine a significant association between advancing paternal age and risk of ASD. Reichenberg et al. used draft board assessment data from 132,271 17-year old Israeli-born Jewish persons. The Israeli draft board assigns a diagnosis based on reviews of records from various sources, including government agencies, medical professionals, and parental interviews rather than-face-to-face assessments.

Despite the lack of a formal medical diagnosis, we obtained results that were significant and consistent with prior research that had used clinical assessment. Our confidence in the accuracy of the parental reporting is further confirmed by the fact that eligibility for specialized health services, including treatment at LBLP, or for any other form of federal support, including tax credits, depends on a proper diagnosis from a health specialist. With a typical recommendation of 6-10 weeks of $20 \mathrm{~h}$ per week of oneon-one intervention, treatment at LBLP comes at a high price and parents almost always seek partial or full reimbursement from their school district. Proper diagnosis prior to treatment also plays a role when filing for educational loans, an option parents often choose to cover LBLP treatment expenses, since school district reimbursements are often delayed and never guaranteed. As the parents' ability to meet these financial requirements depends upon having a clinical diagnosis prior to treatment, it would seem that children seen at LBLP would have received a clinical assessment that confirmed their diagnosis at some point in their history.

We also caution that the Lindamood-Bell clientele and database consist of a specific slice of the population: ASD and dyslexic children with problems in reading and reading comprehension but with some hope for academic improvement and with access to remedial treatment. Due to the limitations of the data stored in the LBLP archive, we could not directly compare the ASD group to a typically developing control group, nor did we have a choice in the measures used to gather the data. Working with standard scores was our way to compare the data to population norms. Clearly, more research examining the disassociation between decoding and comprehension in ASD is needed to understand the origin of this asymmetry and to develop more effective treatment. 
Acknowledgments The authors acknowledge Erica Meyer and Andrea Richards, thesis reviewers, at Antioch University Los Angeles, Nancy Bell, Dave Hungerford, and Robert Tifler at LindamoodBell Learning Processes in San Luis Obispo, California, USA, and Bill Meis.

Open Access This article is distributed under the terms of the Creative Commons Attribution Noncommercial License which permits any noncommercial use, distribution, and reproduction in any medium, provided the original author(s) and source are credited.

\section{References}

American Psychiatric Association. (2000). Diagnostic and statistical manual of mental disorder (text revision). Washington, DC: Author.

Banas, N. (1989). Detroit tests of learning aptitude (2nd ed.). Novato, CA: Academic Therapy Publications.

Beaton, A. (2004). Dyslexia, reading and the brain. New York: Psychology Press.

Bishop, D., \& Snowling, M. (2004). Developmental dyslexia and specific language impairment: Same or different? Psychological Bulletin, 130, 858-886.

Bowers, P. (1993). Text reading and rereading: Predictors of fluency beyond word recognition. Journal of Reading Behavior, 25, 133-153.

Bryson, S. (1983). Interference effects in autistic children: Evidence for the comprehension of single stimuli. Journal of Abnormal Psychology, 92, 250-254.

Catts, H., \& Kamhi, A. (2005). Language and reading disabilities (2nd ed.). Needham Heights, MA: Allyn \& Bacon.

Dunn, L., \& Dunn, L. (1997). The peabody picture vocabulary test (3rd ed.). Circle Pines, MN: American Guidance Service.

Eskes, G., Bryson, S., \& McCormick, T. (1990). Comprehension of concrete and abstract words in autistic children. Journal of Autism and Developmental Disorders, 20(1), 61-73.

Frith, U. (2003). Autism (2nd ed.). Oxford, UK: Blackwell.

Frith, U., \& Snowling, M. (1983). Reading for meaning and reading for sound in autistic and dyslexic children. British Journal of Developmental Psychology, 1, 329-342.

Goldstein, G., Minshew, N., \& Siegel, D. (1994). Age differences in academic achievement in high-functioning autistic individuals. Journal of Clinical and Experimental Neuropsychology, 16, 671-680.

Griswold, D., Barnhill, G., Myles, B., Hagiwara, D., \& Simpson, R. (2002). Asperger syndrome and academic achievement. Focus on Autism and Other Developmental Disabilities, 17, 94-102.

Hammill, D. (1991). Detroit Tests of Learning Aptitude (4th ed.). Austin, TX: PRO-ED.

Harm, M., \& Seidenberg, M. (2000). Are there orthographic impairments in phonological dyslexia? Cognitive Neuropsychology, 18, 71-92.

International Dyslexia Association (2002). Revised definition from the International Dyslexia Association. Retrieved electronically on August 12, 2009 from http://www.dys-add.com/define.html\# revised.

Iwanga, R., Kawasaki, C., \& Tsuchida, R. (2000). Comparison of sensory-motor and cognitive function between autism and Asperger syndrome in preschool children. Journal of Autism and Developmental Disorders, 30, 16-174.

Kanner, L. (1943). Autistic disturbances of affective contact. The Nervous Child, 2, 217-250.
Katzir, T., Yongsuk, K., Wolf, M., O’Brien, B., Kennedy, B., Lovett, M., et al. (2006). Reading fluency: The whole is more than the parts. Annals of Dyslexia, 53(1), 51-82.

Klin, A., Volkmar, F., Sparrow, S., Cicchetti, D., \& Rourke, B. (1995). Validity and neuropsychological characterization of Asperger syndrome: Convergence with nonverbal learning disabilities syndrome. Journal of Child Psychology and Psychiatry, 36, 1127-1140.

Lindamood, C., \& Lindamood, P. (2004). Lindamood auditory conceptualization test. Austin, TX: PRO-ED.

Lindamood-Bell Learning Processes (2007) 2006 Learning Centers' Results. Retrieved September 18, 2007, from http://www.linda moodbell.com/downloads/pdf/research/clinical\%20stats\%202005. pdf.

Mann, V. (2002). Reading disorders, developmental. In V. Ramachandran (Ed.), The encyclopedia of the human brain (pp. 141154). San Diego, CA: Academic Press.

Mann, V., Shankweiler, D., \& Smith, S. (1984). The association between comprehension of spoken sentences and early reading ability: The role of phonetic representation. Journal of Child Language, 11, 627-643.

Minshew, N., Goldstein, G., Taylor, H., \& Siegel, D. (1994). Academic achievement in high functioning autistic individuals. Journal of Clinical and Experimental Neuropsychology, 16(2), 261-270.

Mirenda, P. (2003). "He's not really a reader...": Perspectives on supporting literacy development in individuals with autism. Topics in Language Disorders, 23(4), 271-282.

Mirenda, P., \& Erickson, K. (2000). Augmentative communication and literacy. In A. M. Wetherby \& B. M. Prizant (Eds.), Autism spectrum disorders: A transactional developmental perspective. Baltimore, MD: Paul H. Brooks.

Nation, K. (1999). Reading skills in hyperlexia: A developmental perspective. Psychological Bulletin, 125(3), 338-355.

Nation, K., Clarke, P., Wright, B., \& Williams, C. (2006). Patterns of reading ability in children with autism spectrum disorder. Journal of Autism and Developmental Disorders, 36(7), 911919.

Nation, K., \& Norbury, C. (2005). Why reading comprehension fails. Topics in Language Disorders, 25(1), 21-32.

Nation, K., \& Snowling, M. (1997). Assessing reading difficulties: The validity and utility of current measures of reading skill. British Journal of Educational Psychology, 67, 359-370.

National Institute of Health (2002). Dyslexia definition. Retrieved electronically on August 12, 2009 from http://www2.ednet10. net/dyslexia/Dyslexia-Definition.html.

O'Connor, N., \& Hermelin, B. (1994). Two autistic savant readers. Journal of Autism and Developmental Disorders, 24(4), 501-515.

O'Connor, I., \& Klein, P. (2004). Explorations of strategies for facilitating the reading comprehension of high-functioning students with autism spectrum disorders. Journal of Autism and Developmental Disorders, Vol., 34(2), 115-127.

Ozonoff, S., Rogers, S., \& Pennington, B. (1991). Asperger's syndrome: Evidence of an empirical distinction from high functioning autism. Journal of Child Psychology and Psychiatry, $32,1107-1122$.

Ozonoff, S., South, M., \& Miller, J. (2000). DSM-IV defined Asperger syndrome: Cognitive behavioral and early history differentiation from high-functioning autism. Autism: International Journal of Research and Practice, 4, 29-46.

Reichenberg, A., Gross, R., Weiser, M., Bresnahan, M., Silverman, J., Harlap, S., et al. (2006). Advancing paternal age and autism. Archives of General Psychiatry, 63, 1026-1032.

Ricks, D., \& Wing, L. (1975). Language, communication, and the use of symbols in normal and autistic children. Journal of Autism and Childhood Schizophrenia, 5, 191-221. 
Shankweiler, D., Smith, S., \& Mann, V. (1984). Repetition and comprehension of spoken sentences by reading disabled children. Brain and Language, 23, 241-257.

Slosson, R. (1990). Slosson oral reading test-revised. East Aurora, NY: Slosson Educational Publishing.

Smith, S., Mann, V., \& Shankweiler, D. (1986). Spoken sentence comprehension by good and poor readers: A study with the token test. Cortex, 22, 627-632.

Snowling, M. (2000). Dyslexia. Oxford, UK: Blackwell.

Sparks, R. (1995). Phonemic awareness in hyperlexic children. Reading and Writing, 7, 217-235.

Tager-Flusberg, H. (1981). On the nature of linguistic functioning in early infantile autism. Journal of Autism and Developmental Disorders, 11, 45-56.

Tager-Flusberg, H., Calkins, S., Nolin, T., Baumberger, T., Anderson, M., \& Chadwick-Denis, A. (1990). A longitudinal study of language acquisition in autistic and Down syndrome children. Journal of Autism and Developmental Disorders, 14, 281-289.
Tager-Flusberg, H., \& Joseph, R. (2003). Identifying neurocognitive phenotypes in autism. Philosophical Transactions of the Royal Society of London Series B-Biological Sciences, 358(1430), 303314.

Wahlberg, T., \& Magliano, J. (2004). The ability of high function individuals with autism to comprehend written discourse. Discourse Processes, 38, 119-144.

Wiederholt, J. (1991). Gray oral reading tests-diagnostic. Austin, TX: PRO-ED.

Woodcock, H. (1987). Woodcock reading mastery tests-revised. Circle Pines, MN: American Guidance Service.

Ziegler, J., \& Goswami, U. (2006). Reading acquisition, developmental dyslexia, and skilled reading across languages: A psycholinguistic grain size theory. Psychological Bulletin, 131(1), 3-29. 